\title{
PERDAS OCASIONADAS POR LESÕES EM CARCAÇAS BOVINAS E SEU REFLEXO ECONÔMICO NO ESTADO DO PARANÁ
}

\author{
(Losses occasioned by injuries in bovine carcass and its economic reflection in the \\ state of Paraná)
}

\author{
Aline Souza Sornas ${ }^{1}$, Paulo Rossi Júnior, Fernanda Fragoso Moizes
}

1Correspondência: aline.ss@zootecnista.com.br

RESUMO: Das 253.583 carcaças avaliadas no período de janeiro de 2012 até dezembro de 2014, em parceria com o LAPBOV-UFPR e um frigorífico da região metropolitana de Curitiba, estimou-se a perda anual de 45 toneladas de carne lesionada, representando uma perda monetária de $\mathrm{R} \$ 309$ mil. A maior incidência de machucaduras ocorreu na região do quarto traseiro da carcaça, resultando em perdas econômicas ainda mais expressivas por conter os cortes cárneos mais valorizados no mercado, além de reduzir o tamanho, aspecto e aparência de cortes como o contra filé e a picanha, reduzindo a qualidade do produto. Em relação ao bem-estar animal, os resultados obtidos das perdas econômicas e de qualidade de carcaça são reflexos do manejo inadequado dos animais no pré-abate, e representaram $10,3 \%$ das carcaças avaliadas que continham ao menos uma lesão. O reflexo destes valores é impactante na economia estadual, considerando o abate de $2014 \mathrm{em}$ todo o Estado, o valor representativo da perda seria em média de $R \$ 8,3$ milhões a cada ano. $O$ impacto é direcionado para a comercialização do produto, pois os consumidores se preocupam com questões que envolvem a qualidade dos produtos que consomem, como a origem e o bem-estar dos animais. Os dados levantados neste trabalho contribuíram para dimensionar as perdas por lesões nas carcaças bovinas, e com isso, é possível exercer um manejo pré-abate mais humanizado, de forma a garantir bem-estar aos animais, reduzindo consideravelmente as perdas.

Palavras-chave: abate humanitário; bem-estar animal; contusões; machucaduras; manejo pré-abate; rendimento de carcaça

ABSTRACT: Of 253583 carcasses evaluated in period of january 2012 to december 2014, in partnership with the LAPBOV-UFPR and a slaughterhouse in the metropolitan region of Curitiba, estimated the annual loss of 45 tons of diseased meat, representing a monetary loss of $R \$ 309,00$. The highest incidence of bruising occurred in the carcass from hindquarters region, resulting in even more significant economic losses contain the most valuable meat cuts in the market, while reducing the size, look and feel of courts as strip steak and top sirloin, reducing product quality. In relation to animal welfare, the results of the economic losses and carcass quality are reflections of inappropriate handling of animals before slaughter, and represented $10.3 \%$ of the evaluated carcasses containing at least one injury. The reflection of these values is impacting on the state economy, considering the 2014 slaughter throughout the state, the representative value of the loss would be an average of $R \$ 8.3$ million each year. The impact is directed to the marketing of the product because consumers care about issues surrounding the quality of the products they consume, as the origin and animal welfare. The data collected in this study contributed to scale losses lesions in cattle carcasses, and it is possible to have a more humane preslaughter management, to ensure well-being of the animals, reducing the losses considerably.

Key Words: humane slaughter; animal welfare; bruising; bruises; pre-slaughter management; carcass yield 


\section{INTRODUÇÃO}

A pecuária bovina brasileira tem mostrado importantes ganhos de produtividade na última década, com rebanho estimado em 212 milhões de cabeças e um aumento de $46,3 \%$ na produção de carne (BRASIL, 2015). De acordo com os números da pecuária paranaense elaborado pelo SEAB, em 2014 o número de bovinos abatidos com serviço de Inspeção Federal, Estadual e Municipal foi de 1.450 .453 cabeças com acréscimo de 1,8\% de cabeças em relação ao ano anterior (SEAB, 2015). Em termos de exportação, dados do Ministério da Agricultura, Pecuária e Abastecimento apontam que desde 2008 o Brasil se consolidou entre os maiores exportadores de carne bovina com vendas em mais de 180 países. A expectativa é que até 2020 a produção nacional de carne bovina suprirá $44,5 \%$ do mercado mundial. (BRASIL, 2015b) e as projeções mostram um crescimento de $2,1 \%$ ao ano e valores elevados na próxima década para atender 0 consumo doméstico e às exportações, em especial para 0 período de entressafra (junho à novembro), onde historicamente os preços se elevam pela redução na oferta de animais terminados em decorrência da menor disponibilidade forrageira (SORNAS et al., 2013).
O crescimento geral da produção e das exportações do agronegócio brasileiro assegura ao país papel de destaque no mercado internacional, estando entre as principais potências mundiais de produção agropecuária. A tendência é a de intensificação da atividade acompanhando a melhoria da eficiência de produção verificada nos últimos anos. O Paraná tem destaque na diferenciação do produto por melhor qualificação da pecuária de corte, com uso de forragens de qualidade e a eficiência das raças e cruzamentos utilizados.

A qualidade da carne é influenciada por vários aspectos, envolvendo principalmente as etapas do manejo pré-abate, como o manejo na propriedade para separar os animais que irão para o abate, o embarque, o transporte, o desembarque e o manejo no frigorífico até o momento do abate. Segundo Belk (2002), entre a saída da propriedade e o abate, os animais são submetidos à remoção de seu ambiente doméstico e expostos a estressores como o ruído, privação de comida e água, vibração e velocidade, temperaturas extremas, novos agrupamentos sociais e superlotação. Esses estressores muitas vezes provocam respostas comportamentais e fisiológicas causando desde contusões, 
fraturas, arranhões, exaustão metabólica, desidratação, insolação, até a morte.

Os estímulos com cutucões e choques elétricos para acelerar 0 processo de embarque deixam os animais nervosos e mais agressivos aumentando o risco de acidentes quando se atiram contra as grades do caminhão, pulam sobre outros animais, escorregam e caem, ou ainda agridem com cabeçadas e coices (PARANHOS DA COSTA et al., 2002). Em relação ao transporte, Andrade et al. (2008), afirmam que em condições desfavoráveis o sistema de transporte pode levar à morte e ser responsável pelas principais contusões observadas na inspeção post-mortem no frigorífico, principalmente pela forma inadequada de contenção e manipulação (estresse psicológico), ou ainda proporcionar fome, sede, fadiga e machucaduras (estresse físico) (GRANDIN, 2014).

Reduzir o estresse durante 0 manejo contribui para melhorar a produtividade e evitar alterações fisiológicas que possam afetar a qualidade da carne (GRANDIN, 1989). Paranhos da Costa et al.(2002) relatam que quando $\mathrm{o}$ animal sofre estresse, compromete $\mathrm{o} \mathrm{pH}$ post-mortem com implicações para maciez, capacidade de retenção de água, fragilização da estrutura miofibrilar e cor do corte. O estresse durante manejo antes do abate, segundo Pires et al. (2010), deixa os animais agitados, e pode induzir a ocorrência de DFD (Dark, Firm and Dry), ou carne de aparência escura, dura e seca, ocasionada pelo gasto de glicogênio muscular e depleção das reservas, provocando queda lenta de $\mathrm{pH}$. A reserva de glicogênio é importante para que ocorra a queda rápida do $\mathrm{pH}$ muscular post-mortem, necessária para transformar músculo em carne, porém, o pH elevado (>6) favorece 0 desenvolvimento microbiológico e a alta retenção de água resultando em má aparência, sabor não característico de carne fresca e menor durabilidade de prateleira (SCANGA, 1998).

Grandin (2007) relata que contusões custam milhões de dólares para a indústria de carne anualmente, em geral, os problemas ocasionados pelo manejo inadequado dos animais no pré-abate geram grandes perdas econômicas e de qualidade nas carcaças, pois os locais afetados devem ser condenados parcialmente ou totalmente dependendo da gravidade (SANTOS \& MOREIRA, 2011), além de comprometer o rendimento dos cortes. A carne com contusão que é removida não pode ser utilizada como alimento, 
pois não é aceita pelo consumidor na forma in natura e nem no processamento, por se decompor rapidamente (SOUZA \& FERREIRA, 2007). De acordo com Polizel Neto et al. (2015), os principais cortes comerciais localizam-se na região do lombo e pernil, como alcatra, picanha, maminha, coxão mole e contrafilé. Como os cortes seguem um padrão de qualidade, a existência de lesões exige que os cortes sejam refilados, perdendo suas características e valor econômico.

Para Pires et al. (2010) a carne de boa qualidade não deve apresentar comprometimentos que limitem a estocagem e manipulação, devendo atingir os padrões organolépticos desejados pelo consumidor. Para obtenção de uma carne com qualidade e padrões superiores, é necessário levar em consideração 0 bem-estar dos animais destinados ao abate, devendo prevalecer as condições humanitárias em todos os momentos que precedem o abate, visando a atual preocupação do mercado consumidor com a origem, a qualidade e a rastreabilidade dos produtos.

A compilação dos dados de abate de um frigorífico na região metropolitana de Curitiba, juntamente com os dados da cotação da arroba do boi gordo e vaca gorda para o Estado do Paraná (indicador LAPBOV - UFPR) possibilitou quantificar as perdas em quilograma por carcaça machucada e as perdas monetárias representativas para o setor. Os resultados obtidos permitiram uma reflexão mais aprofundada acerca da importância em exercer um manejo adequado para reduzir as injúrias e consequentes perdas nas carcaças bovinas.

Como as pesquisas relacionadas à perda por lesões em carcaças bovinas ainda são poucas e levam em conta a perda por animais abatidos no geral, o trabalho contribui com informações mais precisas por considerar a perda por carcaça lesionada, sendo assim de grande importância no cenário econômico da pecuária estadual, além de abordar questões de qualidade de carcaça e bem-estar animal, hoje tão difundidas na produção pecuária.

\section{MATERIAL E MÉTODOS}

O trabalho foi executado em parceria com o Laboratório de Pesquisa em Bovinocultura de corte (LAPBOV) do Departamento de Zootecnia da Universidade Federal do Paraná juntamente com um frigorífico da região metropolitana de Curitiba, que forneceu o banco de dados de avaliação de carcaças de 3 anos (janeiro de 2012 até 
dezembro de 2014), totalizando 253.583 carcaças avaliadas no período.

Os dados coletados do indicador LAPBOV para os preços do boi gordo e vaca gorda seguem o mesmo período, utilizando as médias ponderadas do Estado do Paraná para cada mês.

Os dados em porcentagem de fêmeas e machos abatidos, bem como as porcentagens de machucaduras por local afetado em relação ao total de abate, foram retirados do Programa de Análise de Qualidade de Carcaças Bovinas (LAPBOV) com base no banco de dados de 395 mil carcaças, realizado desde março de 2010 até dezembro de 2014.

Para a estimativa do peso das perdas foram utilizadas informações de um experimento realizado em 2013 no próprio frigorífico (WOLFF, 2013), onde foram avaliadas 11.216 carcaças com perda total de $9.982,42 \mathrm{~kg}$ de carne lesionada em 37 dias de coleta. Utilizouse o total de peso das partes lesionadas para cada uma das 6 regiões de carcaça analisadas (dianteiro, traseiro, costela, vazio, contra filé e picanha) dividido pela quantidade de animais efetivamente machucados em cada região anatômica (dados do Programa de Análise de Qualidade de Carcaças Bovinas - LAPBOV) e assim, conseguiuse a média precisa de perda por região, por animal afetado. Foi então extrapolado para a quantidade de animais com machucaduras verificados a cada mês no período de janeiro de 2012 à dezembro de 2014.

Foram editadas as informações mensais separadas por sexo e local afetado, considerando as regiões anatômicas: dianteiro, traseiro, costela, vazio, contra filé e picanha. Através da obtenção quantificada em quilograma por carcaça por região afetada foi dimensionada a perda total mensal e anual para a fase em questão (janeiro de 2012 à dezembro de 2014). Assim, foram determinados os valores totais por somatório para machos e fêmeas separadamente.

Os dados de abate para o Estado do Paraná em porcentagem de machos e fêmeas possibilitaram dimensionar a perda total real para 0 setor ao extrapolar para a quantidade de animais machucados em relação à quantidade abatida, e com isso, fazer uma projeção anual de perdas monetárias tanto com base no valor por arroba, quanto no valor por quilograma por corte.

\section{RESULTADOS E DISCUSSÃO}

Das 253.583 carcaças avaliadas no período de janeiro de 2012 até dezembro de 2014, 26.155 animais apresentaram ao menos uma parte 
machucada na carcaça, representando $10,3 \%$ do total em que $8,1 \%$ machos e $18 \%$ fêmeas apresentaram machucaduras dentro do total abatido. As regiões de maiores danos foram: traseiro $(7,2 \%)$, vazio $(5,4 \%)$ e costela $(3,7 \%)$. No geral, houve uma perda de $135.499,64 \mathrm{~kg}$ de carne lesionada em três anos de análise, o que representou uma perda de $R \$ 925.559,40$, com base nos valores médios mensais da arroba do boi gordo e vaca gorda para o período (cotação LAPBOV - UFPR) (Tabela 1). Aproximadamente $\mathrm{R} \$ 309$ mil e 45 toneladas de carne por ano foram perdidas em apenas um frigorífico.

\begin{tabular}{|c|c|c|c|}
\hline $2012 \cdot 2014$ & Machos & Fèmeas & Total \\
\hline Perdas (kg) & 75.493 .25 & 60.00639 & 135.499 .64 \\
\hline Perdas (RS) & 534.778 .78 & 390.782 .62 & 925.559 .40 \\
\hline
\end{tabular}

Ao utilizar os dados apresentados na Tabela 2, contendo os pesos médios de carne lesionada por carcaça de cada região analisada e a porcentagem de ocorrência de lesões para machos e fêmeas, devido ao tamanho expressivo do banco de dados utilizado, poderiam servir de base para estimar a perda com outros números de abate, dependendo das condições próprias de cada frigorífico.



Considerando que em 2014 o número de bovinos abatidos com serviço de Inspeção Federal, Estadual e Municipal foi de 1.450 .453 cabeças para o Estado do Paraná (SEAB, 2015), e que destes, $77,6 \%$ foram machos e 22,5\% foram fêmeas (dados do Programa de Análise de Qualidade de Carcaças Bovinas - LAPBOV), estimouse que houve uma perda total de $763.998,87 \mathrm{~kg}$ de carne lesionada e $\mathrm{R} \$ 7.638 .006,46$ de perda monetária (tomando como base 0 valor de R\$149,97/@ do boi gordo e $\mathrm{R} \$ 140,95 / @$ da vaca gorda cotados em 10 de dezembro de 2015 pelo LAPBOV - UFPR), conforme mostra a Tabela 3. Já ao considerar os valores por quilograma dos cortes no mercado atacadista, a perda total foi de $\mathrm{R} \$ 8.261 .579,61$ (com base nos preços cotados em 10 de dezembro de 2015 cedidos pelo frigorífico do experimento, onde: dianteiro $=R \$ 8,30 / \mathrm{kg}$ traseiro $=R \$$ $14,00 / \mathrm{kg}$ costela $=R \$ 10,45 / \mathrm{kg}$ vazio $=$ $R \$ 16,50 / \mathrm{kg}$ contra filé $=R \$ 14,90 / \mathrm{kg}$ e 
picanha $=\mathrm{R} \$ 36,00 / \mathrm{kg}$ ) conforme Tabela 4.

\begin{tabular}{|c|c|c|}
\hline \multirow[b]{2}{*}{ Partes lesionadas } & \multicolumn{2}{|c|}{ Dos 1.450 .453 animais abatidos: } \\
\hline & $\begin{array}{c}\text { Perdes em } \mathrm{kg} \\
\text { (machos + femeas) }\end{array}$ & Perdas em RS \\
\hline dianbeiro & 3563.318 .835 & $2.967 .695,73$ \\
\hline traseiro & $97.765,882$ & 136872235 \\
\hline coskels & 2038951,155 & 2.130 .66236 \\
\hline vazio & 82.786,275 & $1,448.473,53$ \\
\hline contra tie & $14.190,338$ & $211.496,04$ \\
\hline picanha & $4.016,383$ & $144,589,80$ \\
\hline Total & 763998,867 & $8.261 .579,61$ \\
\hline
\end{tabular}

A Figura 1 mostra algumas imagens das carcaças que apresentavam lesões e foram comprometidas pela perda após a limpeza (toalete).

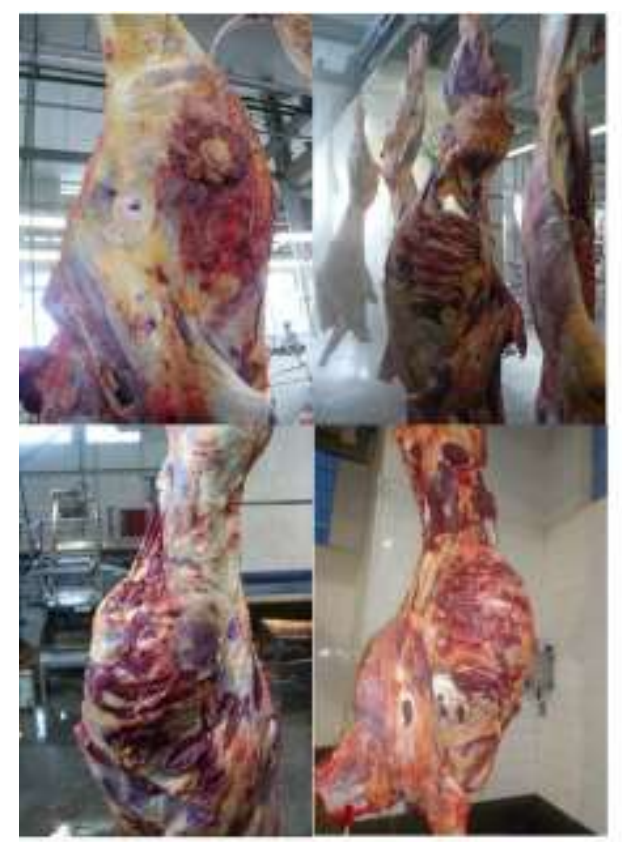

Figura 1. Carcaças lesionadas apos impeza.

Fonter: Folos cedidas por Fernanda Moizes (Programa de Analise de Qualidade de Carcaças Bovinas - LAPBOV)

As metodologias dos trabalhos relacionados com o tema variam, baseando-se sempre no total de animais abatidos e não no total de animais machucados, bem como a amostragem e os valores por arroba.
Em mapeamento realizado por Peres et al. (2010), registraram que o quarto traseiro também foi a região mais atingida, resultando em perdas econômicas significativas, com 31,2\% de frequência no coxal e $20,5 \%$ no sacral. Ao avaliar lesões de carcaças, Braga et al. (2010) detectaram que $92,9 \%$ das carcaças apresentaram lesões, onde as áreas de ponta de agulha e traseiro foram as que mais apresentaram lesões, $51,5 \%$ e $34 \%$ respectivamente. Santos \& Moreira (2011) constataram que $92,1 \%$ das carcaças avaliadas tinham algum tipo de lesão, e pela avaliação da gravidade predominou lesões recentes indicando que ocorreram em curto espaço de tempo entre o embarque e o abate, também observaram que houve maior ocorrência de contusões no quarto traseiro, decorrente da utilização de guizos e paus para conduzir os animais. Em trabalho com 1.523 bovinos abatidos, Grandin (1981) encontrou valor próximo da porcentagem de animais machucados no geral, onde $10,5 \%$ das carcaças apresentaram contusões, porém as principais localizações das lesões foram diferentes: lombo (45\%); dianteiro (23\%) e vazio (15\%). Andrade et al. (2008) também encontram maiores incidências em cortes diferentes, sendo eles: 0 
lagarto $(28,1 \%)$, alcatra $(15,9 \%)$ e coxão duro (14,8\%). Lago et al. (2011) estimaram que os cortes mais afetados foram: costela do traseiro $(38 \%)$, coração da alcatra $(21,2 \%)$ e picanha $(17,2 \%)$.

No presente estudo em média foram encontrados $4,714 \mathrm{~kg}$ de perda por macho machucado $(0,383 \mathrm{~kg}$ por macho abatido) e 5,918kg por fêmea machucada $(1,066 \mathrm{~kg}$ por fêmea abatida), já em termos monetários, foram encontrados $R \$ 33,39$ de perda por macho machucado ( $\mathrm{R} \$ 2,71$ por macho abatido) e $\mathrm{R} \$ 38,54$ por fêmea machucada ( $\mathrm{R} \$ 6,94$ por fêmea abatida).

Andrade et al. (2008)
encontraram média de $0,500 \mathrm{~kg}$ de carne lesionada retirada por animal ao avaliarem a influência do transporte na ocorrência de lesões em carcaças bovinas, e em novo estudo os mesmos autores (ANDRADE et al., 2009) concluíram através da avaliação da coloração das lesões que a maioria ocorreu nas últimas 24 horas que antecedem 0 abate, tendo relação novamente com 0 transporte inadequado dos bovinos. Já as perdas econômicas no trabalho de Santos \& Moreira (2011) foram calculadas para $0,310 \mathrm{~kg}$ de contusões por animal, representando aproximadamente $\mathrm{R} \$ 1,86 /$ animal (considerando a cotação de $\mathrm{R} \$ 88,20 / @)$. E com base no preço da arroba de $R \$ 70,00$, estimou-se a perda de $R \$ 1,15$ por animal no trabalho de Lago et al. (2011). Polizel Neto et al. (2015) estimaram que a perda anual para um frigorífico de médio porte poderia ser superior a $\mathrm{R} \$ 200$ mil, o que foi verificado no presente estudo, com perda estimada em aproximadamente $\mathrm{R} \$ 309$ mil por ano para um frigorífico de médio a grande porte.Em relação aos custos, segundo Grandin (1981) o pecuarista que vende o gado por peso vivo apresentou animais com o dobro de contusões que o gado vendido por peso de carcaça, neste último caso, como o produtor paga pelas contusões, isso acaba sendo um incentivo para reduzilos e melhorar o manejo.

\section{CONCLUSÃO}

Estimou-se a perda anual de 45 toneladas de carne lesionada, representando uma perda monetária de $\mathrm{R} \$ 309 \mathrm{mil} / \mathrm{ano}$. O reflexo destes valores é impactante na economia estadual, considerando o abate de 2014 em todo - Estado, o valor representativo da perda seria em média de $\mathrm{R} \$ 8,3$ milhões a cada ano. Sendo que as perdas, apesar de elevadas, não são dimensionadas e acabam sendo absorvidas, ou pelo pecuarista quando vende o animal pelo peso da carcaça, 
ou pelo frigorífico ao pagar pelo peso vivo do animal (prática mais usual). Também verificou-se maior incidência de machucaduras na região do quarto traseiro da carcaça, resultando em perdas econômicas ainda mais expressivas por conter os cortes cárneos mais valorizados no mercado.

Os resultados dimensionados em termos de qualidade de carcaça são altamente impactantes por reduzir o tamanho, aspecto e aparência dos cortes, principalmente dos cortes com alto valor agregado como o contra filé e a picanha, além da deterioração precoce por reduzir a vida útil da carne, trazendo riscos de segurança alimentar. Assim, a carne lesionada deve ser descartada, não podendo ser utilizada nem no processamento nem como nenhum outro subproduto.

Em relação ao bem-estar animal, os resultados obtidos das perdas econômicas e de qualidade de carcaça são reflexos do manejo inadequado dos animais no pré-abate, e representaram $10,3 \%$ das carcaças avaliadas que continham ao menos uma lesão no presente trabalho. $O$ impacto é direcionado para a comercialização do produto, pois os consumidores se preocupam com questões que envolvem a qualidade dos produtos que consomem, como a origem e o bem- estar dos animais para garantir produtos com boa aceitação no mercado.

Diante da importância que a bovinocultura de corte exerce sobre o cenário econômico no Estado do Paraná, representando papel de destaque para o equilíbrio da balança comercial, os dados levantados neste trabalho contribuíram para dimensionar as perdas por lesões nas carcaças bovinas, tanto em quantidade quanto em qualidade. Com isso, é possível exercer um manejo pré-abate mais humanizado, de forma a garantir bemestar aos animais e consequentemente, reduzir consideravelmente as perdas.

\section{REFERÊNCIAS}

ABIEC. Associação Brasileira das Indústrias Exportadoras de Carne. Exportações Brasileiras de Carne Bovina. Disponível em <http://www.abiec.com.br>. Acesso em agosto de 2015.

ANDRADE, E. N.; SILVA, A. M. S.; ROÇA, R. O. et al. Ocorrência de lesões em carcaças de bovinos de corte no Pantanal em função do transporte. Ciência Rural, Santa Maria, v.38, n.7, p.1991-1996, 2008.

ANDRADE, E. N.; SILVA, A. M. S.; ROÇA, R. O. Manejo pré-abate de bovinos de corte no Pantanal, Brasil. Archivos de Zootecnia, v.58, n.222, p.301-304, 2009.

BELK, K. E.; SCANGA, J. A.; SMITH, G. C.; GRANDIN, T. The Relationship Between Good Handling / Stunning and Meat Quality in Beef, Pork, and Lamb. 
In: Animal Handling and Stunning Conference, Colorado. Proceedings... Colorado: Colorado State University, 2002. 25p.

BRAGA, J. S.; MACHADO, M. F.; POLONIO, J. D.; MOLENTO, C. F. M. Lesões de carcaças e grau de bemestar de bovinos de corte em frigorífico da região sudeste do Brasil. In: Reunião anual da Sociedade Brasileira de Zootecnia, 47, 2010, Salvador- BA. Anais... Salvador: SBZ, 2010.

BRASIL. Ministério da Agricultura Pecuária e Abastecimento. Estatísticas e dados básicos de economia agrícola. Secretaria de Política Agrícola. Brasília: MAPA, 2015b. 54p.

BRASIL. Ministério da Agricultura Pecuária e Abastecimento. Plano Agrícola e Pecuário 2014/2015. Brasília: MAPA, 2014. 92p.

BRASIL. Ministério da Agricultura Pecuária e Abastecimento. Projeções do Agronegócio - Brasil 2014/15 a 2014/25. Assessoria de Gestão Estratégica. Brasília: MAPA, 2015. 133p.

BRASIL. Ministério da Agricultura Pecuária e Abastecimento. Regulamento da Inspeção Industrial e Sanitária de Produtos de Origem Animal. Secretaria de Defesa Agropecuária- DAS. Departamento de Inspeção de Produtos de Origem Animal- DIPOA. Brasília: MAPA,1997. 241p.

BRIDI A.M. Normas de Avaliação, Classificação e Tipificação de Carnes e Carcaças. Univ. Est. Londrina. 2002.

DINHEIRO RURAL. A pancada que dói no bolso, edição 120 , novembro de $2014 . \quad$ Disponível em:< http://revistadinheirorural.terra.com.br/se cao/agronegocios/>. Acesso em agosto de 2015.

GRANDIN,T. Animal Welfare and humane Slaughter. 2004. Disponível em:

<http://www.grandin.com/references/hu mane.slaughter.html> .Acesso em agosto de 2015.

GRANDIN, T. Animal welfare and society concerns finding the missing link. Meat Science, v. 98, n.3, p.461-469, Novembro 2014.

GRANDIN, T. Assessment of stress during handling and transport. Journal of Animal Science, v.75, p.249-257, 1997.

GRANDIN, T. Behavioral Principles of Livestock Handling. Professional Animal Scientist, v.5, p.1-11, 1989.

GRANDIN, T. Bruise levels on fed and non- fed cattle. In: Livestock Conservation Institute, Kentucky. Proceedings... Kentucky, 1995. p.193201.

GRANDIN, T. Bruises on southwestern feedlot cattle. Journal of Animal Science, v.53, suppl.1, p.213, 1981.

GRANDIN, T. How to Track Down the Cause of Bruising. Dept. of Animal Science. Colorado State University, $2007 . \quad$ Disponível em: <http://www.grandin.com/references/cau se.bruising.html> .Acesso em agosto de 2015.

HOFFMAN, D. E., SPIRE, M. F.; SCHWENKE, J. R.; UNRUH, J. A. Effect of source of cattle and distance transported to a commercial slaughter facility on carcass bruises in mature beef cows. Journal of the American Veterinary Medical Association, Schaumburg, v.212, n.5, 1998.

IBGE. Indicadores IBGE. Estatística da produção pecuária. Disponível em: $<$ http://www.ibge.gov.br/home/estatistica /indicadores/producaoagropecuaria>. Acesso em agosto de 2015.

LAGO, N. C. M. R.; D'AMATO, C. C.; MARCHI, P. G. F. Perdas econômicas por abscessos e hematomas em 
carcaças de bovinos. Revista Eletrônica da Univar, n.6, p.154-157, 2011.

\section{LAPBOV. Laboratório de Pesquisa em} Bovinocultura de corte. Disponível em: <http://www.lapbov.ufpr.br/>. Acesso em outubro de 2015.

NASSIR, L. C. Perdas econômicas ocasionadas por lesões em carcaças bovinas. 2009. São José do Rio Preto, 29f. Monografia (Especialização)Curso de Pós- graduação em Higiene e Inspeção de Produtos de Origem Animal, Instituto Qualittas de PósGraduação.

PARANHOS DA COSTA, M. J. R.; COSTA E SILVA, E. V.; CHIQUITELLI NETO, M.; ROSA, M. S. Contribuição dos estudos de comportamento de bovinos para implementação de programas de qualidade de carne. In: ENCONTRO ANUAL DE ETOLOGIA, $X X, 2002$. Anais... Natal: Sociedade Brasileira de Etologia, 2002, p.71-89.

PARANHOS DA COSTA, M. J. R. Ambiência e qualidade de carne. In: Congresso das Raças Zebuínas, V, 2002. Anais... Uberaba: ABCZ, 2002, p.170-174.

PEIXOTO, A. M. Evolução histórica da pecuária de corte no Brasil. In: PIRES, A.V. Bovinocultura de corte. Volume I. Piracicaba: FEALQ, 2010, Cap.1, p.0310.

PERES, L. M.; OLIVEIRA, A. C.; ELIAS JUNIOR, V. A.; BRIDI, A. M. Frequência de lesões em carcaças bovinas. In: ENCONTRO ANUAL DE INICIAÇÃO CIENTÍFICA, XIX, 2010. Anais... Guarapuava- PR: Unicentro, 2010, p.1014.

PIRES, P. P.; MELO, T. P. O. Desafios para a cadeia produtiva da carne bovina. In: PIRES, A.V. Bovinocultura de corte. Volume II. Piracicaba: FEALQ, 2010, Cap.62, p.1253-1261.
PREVIDI, M. Combatendo a lesão, grande vilã da pecuária. Informativo Beckhauser. ano 14, n.68, 2014. Disponível em: <http://www. beckhauser.com.br/informativo.php>. Acesso em agosto de 2015.

POLIZEL NETO, A.; ZANCO, N.; LOLATTO, D. C. J. et al. Perdas econômicas ocasionadas por lesões em carcaças de bovinos abatidos em matadouro-frigorífico do norte de Mato Grosso. Pesquisa Vet. Bras., v.35, n.4, p.324-328, 2015.

RENNER, R. M. Fatores que afetam o comportamento, transporte, manejo e sacrifício de bovino. 2005.UFRGS, 87p. Tese (Especialização em tecnologia dos produtos de origem animal) - Universidade Federal do Rio Grande do Sul, 2005.

REZENDE, M. A. Características de carcaça e qualidade da carne de vacas de descarte submetidas a duas velocidades de ganho de peso. 2012. Dourados, MS, 53f. Dissertação (Mestrado em Zootecnia)- Curso de Pós-graduação em Zootecnia, Universidade Federal da Grande Dourados.

ROÇA, R. de O. Abate humanitário de bovinos. In: Conferência Virtual Global sobre Produção Orgânica de Bovinos de Corte, I, 2002, Corumbá- MS. Proceedings... Corumbá: Embrapa Pantanal, 2002. 15p.

SANT'ANNA, A. C.; PARANHOS DA COSTA, M. J. R. Como as práticas de BEA podem melhorar a bovinocultura moderna. In: SIMBEA- Simpósio da Ciência do Bem-estar animal, I, 2009, Belo Horizonte. Proceedings... Belo Horizonte, MG: Escola de Veterinária da UFMG, 2009. p.51-57.

SANTOS, A. M.; MOREIRA, M. D. Ocorrência de contusões em carcaças bovinas abatidas em um matadourofrigorífico do triângulo mineiro e suas 
perdas econômicas. Horizonte Científico, v.5, n.2, 2011.

SCANGA, J. A.; BELK, K.E.; TATUM, J.D. et al. Factors Contributing to the Incidence of Dark Cutting Beef. Journal of Animal Science, v.76, p.2040-2047, 1998.

SEAB. Governo do Estado do Paraná. Secretaria de Estado da Agricultura e do Abastecimento. Departamento de Economia Rural. Análise da Conjuntura Agropecuária. SEAB, 2015. Disponível em: $<$ http://www.agricultura.pr.gov.br/conteu do>. Acesso em agosto de 2015.

SORNAS, A. S. et al. Informativo mensal de dezembro. In: LAPBOVLaboratório de Pesquisa em Bovinocultura de corte. No. 21, 2013, p.01-05. Disponível em: $<$ http://www.lapbov.ufpr.br/>. Acesso em agosto de 2015.

SORNAS, A. S.; ROSSI Jr, P.; MOIZES, F. A. F. Impacto do abate de vacas prenhes sob parâmetros de carcaça e sua influência no resultado econômico. Archives of Veterinary Science. v.19, n.4, p.01-08, 2014.

SOUZA, A. A.; FERREIRA, T. I.. Manejo Racional. Perdas econômicas devido ao manejo inadequado de bovinos de corte, 2007. Disponível em: <http://www.beefpoint.com.br/radarestecnicos/manejo-racional/>. Acesso em agosto de 2015.

SMITH, G. C.; GRANDIN, T.; FRIEND, T. H.; LAY, D. Effect of Transport on Meat Quality and Animal Welfare of Cattle, Pigs, Sheep, Horses, Deer, and Poultry, 2004. Disponível em:< http://www.grandin.com/behaviour/effect .of.transport.html>. Acesso em agosto de 2015.

WOLFF, G. Perdas econômicas por lesões em carcaças bovinas. 2013. UFPR, 43p. Tese (Graduação em
Medicina Veterinária) - Universidade Federal do Paraná, 2013.

ZEN, S. De; BARROS, G. S. D. Evolução do mercado brasileiro da carne bovina. In: PIRES, A.V. Bovinocultura de corte. Volume I. Piracicaba: FEALQ, 2010, Cap. 3, p.4151. 